\title{
WILLINGNESS TO PAY FOR ACCESSIBLE ELDERLY HOUSING IN KOREA
}

\author{
So Young LEE ${ }^{1}$, Sung Eun $\mathrm{YOO}^{2, *}$ \\ ${ }^{1}$ Department of Housing and Interior Design, Chung-Ang University, Seoul 06974, Korea \\ 2 Department of Space Design and Fusion Technology, Kunsan National University, Gunsan 54150, Korea
}

Received 05 March 2019; accepted 21 July 2019

\begin{abstract}
The demands and requirements for accessible housing of a diverse population can vary considerably, especially considering that "aging in place" is a growing trend among the elderly. In an aging society, accessibility can be a housingmarket commodity, and the demand in Korea for this commodity is expected to increase. The purpose of this study is to investigate the value of accessible housing and the consumer's willingness to pay (WTP) using the Contingent Valuation Method (CVM). For the analysis, 700 people were interviewed based on the housing type and age group. More than half of the respondents were willing to pay more for accessible housing compared to conventional housing. The WTP amount differed considerably with the age group, gender, housing type, size of unit, and tenure type. The elderly showed a greater WTP than the younger group; higher economic status (as indicated by monthly household income), educational level, and home ownership influenced WTP. The results showed that accessible housing could be an important housing choice for the elderly and can be adopted as an affordable option. Moreover, the results can help reduce the negative perception of accessible housing, which is commonly associated with its supposed high costs.
\end{abstract}

Keywords: accessible housing, willingness to pay, contingent valuation method, elderly, accessibility.

\section{Introduction}

Over the last decades, thousands of affordable, subsidized, and public housing units were demolished in the United States, which resulted in a decreasing number of subsidized housing units. Government housing programs have partnered with the private sector and became part of a market-driven model. This situation led to an increased demand for affordable housing and accessibility modifications for senior residents (McFadden \& Lucio, 2014). With an increase on population aging, the public housing sector needs contribution from the private sector in order to provide affordable and accessible housing environments for the vulnerable aging population.

Similar to the worldwide trends, the elderly population in South Korea has grown, with the proportion of elderly households estimated to be $43.5 \%$ in 2035 from $17.8 \%$ in 2010 (Korea Ministry of Statistics), yet the supply of barrier-free housing units for the elderly are very limited in the housing market. Some barrier-free design elements have been applied only to a limited number of public facilities in apartment complexes. According to the 2007 report from the Ministry of Land, Transport and Maritime Affairs, $63.8 \%$ of the elderly want to live in their own home regardless of their health status, demonstrating "aging in place" as a growing trend. Therefore, there is a need to develop housing options which consider the housing needs of the elderly.

Public housing policies have focused on a vulnerable elderly population. According to the Rules on Housing Supply amended in 2014, elders over 65 or disabled people can be allocated to the ground floor first when they win a housing application. Public rental housing for the elderly include barrier-free design elements such as adjusted closing direction of bathroom door or sliding-type bathroom door, bathroom emergency call, foot lights, and safety handles. However, considering the growing population of elders, supply from the public housing sector is not enough to provide the specific housing demands. The private housing market is needed in a market-driven model.

In addition to that, accessibility in houses might be considered a negative aspect, since it is often regarded as an expensive option which benefits only the disabled (Alonso, 2002; Świeżawska-Ambroziak \& Perez, 2006). However, several studies have shown that the cost for accessibility would become much lower if the housing structures had been built considering barrier-free design

${ }^{\star}$ Corresponding author. E-mail: seyoo@kunsan.ac.kr 
features (Dunn, 1988; Lee, 2014; Schroeder \& Steinfel, 1979). The home environment is a primary context for daily activities. Accessible design involves planning and constructing products and environments that can be accessed and used by people with disabilities (Pirkl, 1994). Alonso (2002) defined accessible housing design or accessible construction characteristics as those that allow ease of access and free movement by all users, including children, elders, and disabled people. Properly designed housing helps support independent living by reducing the physical barriers to a person's daily activities (Fänge \& Iwarsson, 2005). The increased costs of accessible housing would not exceed $6 \%$ of the total housing construction costs if they were incorporated in the initial planning stages. Even in the case of alteration or renovation of existing houses, the cost is only slightly higher compared with the added cost at the planning stage. These studies mainly examined the costs from the perspective of the provider, so it is necessary to explore the costs from the consumer's point of view.

In an aging society, accessible designs are important for the senior residents to live independently within their own homes. However, most of the housing stock has been built without considering accessible designs for residents with functional limitations. Therefore, there is a need to understand the willingness to pay for accessible housing, so housing alternatives and policies can be developed, as well as housing submarkets. Estimations of the willingness to pay for specified improvements of environmental attributes have been applied to the valuation of public goods without market. There are some studies that attempt to obtain an accurate estimate of the benefits in the field of housing policy. In order to overcome negative perception of barrier-free, accessible housing, Alonso (2002) used the CVM to evaluate the benefits of accessible housing features for people with disabilities. His study found that households' willingness to pay for barrier-free, accessible housing was higher than the cost of construction. Alonso recommended representing the fixed bid as a percentage to account for different factors affecting the cost of housing such as size, price, and location. Using a percentage to describe willingness to pay was also less sensitive for respondents because housing, whether rented or purchased, is a relatively high cost. The study found barrierfree building to be socially profitable, and suggested that housing developers need to meet the needs of disabled populations. The results compared accessible housing values with actual construction costs, and evaluated what percentage of accessible housing features could be applied to different types of housing. However, the study did not investigate differences between older and younger adults in terms of their views toward accessible housing and their willingness to pay for specific features.

Other studies of housing for elderly, independent living focused on physical characteristics (Demirkan, 1991, 2007; Lawlor \& Thomas, 2008; Memken \& Earley, 2007) or preferences (Sagdic \& Demirkan, 2000), rather than on the cost factor. These studies included the standards and references that guide the design process for disabled and elderly housing. Memken and Earley (2007) showed that accessible features offer benefits to individuals of any age and ability level. Additionally, Sagdic and Demirkan (2000) found that there were gender differences in preferences for interior use that had not been considered in the design standards.

Therefore, as the aging proportion of the population significantly increases, it is necessary to investigate how much younger and older adults are willing to pay for accessible housing features. The purpose of this study is to investigate the value of accessible housing attributes, and to estimate the degree of willingness to pay (WTP) for such housing using the contingent valuation method (CVM).

\section{Literature review}

\subsection{Accessible design in housing environments}

The Housing Enabler has been established as a promising instrument to assess physical environmental barriers and person-environment fit within the houses and their close exterior surroundings (Iwarsson \& Slaug, 2010). Lien, Steggell, Slaug, and Iwarsson (2016) assessed the environment accessibility of traditional single-family and multifamily housing (e.g., apartments, condos, townhomes) using the Housing Enabler Instrument to inform appropriate housing environment interventions.

Schroeder and Steinfeld's (1979) study compares the costs of renovation projects with the additional costs of adding barrier-free specifications to the design of new houses. The additional construction costs for new houses ranged from $0.006 \%$ to $0.13 \%$, and the costs of retrofitting for accessibility, compared with the original construction costs from $0.12 \%$ to $0.5 \%$. When barrier-free features are defined in the design stage of a building, costs are reduced 4 to 35 times. Dunn (1988) estimated that the cost increase for a barrier-free construction ranged from $0.25 \%$ to $4.2 \%$, depending on the housing type and the number of housing units, regardless of being a new construction or a renovation. He also estimated that this increase would not exceed $1 \%$ of the total construction costs if $10 \%$ of the units were made accessible. Gaia’s (2008) study showed that interventions to make old buildings accessible are not expensive. The $2.1 \%$ added cost was mainly due to need for common new renovations, such as stairs or speaker systems to modernize the buildings, rather than for accessibility solutions. According to Lee (2014), the additional cost to construct accessible housing ranges from $0.5 \%$ to $5.3 \%$ in single-family houses and $0.5 \%$ to $3.1 \%$ in multifamily housing. For alteration or renovation, it ranged from $9.4 \%$ to $15.7 \%$ of the construction cost.

\subsection{The benefits of accessibility}

The expected benefits of barrier-free designs can be split into two groups: those that are tangible and financially quantifiable, and intangible benefits that are more difficult 
to measure but may bring indirect or derivative advantages (Chollet, 1979; Frisch, 1998; Ratzka, 1994). Tangible benefits may include lower social pension costs, due to a higher rate of employment, reduction in accidents and their related costs in terms of health services and loss of production, and increase in housing quality that most accessibility features entail.

The benefits also include facilitated independent living. Thus, at the individual level, it can increase participation in the labor market and earnings from employment, as well as improve health and alleviate risks (Chollet, 1979). It generates a more convenient environment in the form of wider doors and hallways, safer kitchen and bathrooms, and decreased demand for institutional residential living by older people, who are often forced to leave their own inaccessible houses (Ratzka, 1994).

The study commissioned by the US Department of Housing and Urban Development, carried out by Chollet (1979), presented a cost-benefit analysis on the removal of architectural barriers from residential buildings. Cost comparisons between institutional and community living for elders and people with disabilities were conducted to estimate the benefits of renovating existing buildings and removing architectural barriers. In three types of residential structures, high-rise apartments, garden apartments, and single-family homes, benefits included reduced costs for personal care service due to increased independence in terms of living arrangements.

Frisch (1998) estimated the benefits of accessibility in the community by attempting to calculate the production lost by the economy as a result of an inaccessible environment. Community productivity loss can also derive from unemployment among people with disabilities due to inadequate workplace access.

The estimation of benefits from barrier-free building has always required analysis of indirect factors, such as calculating the savings in social services and hospitalization costs, or the gains from adaptations made possible by the increased accessibility. Alonso's (2002) study used the CVM to make a direct appraisal of the benefits from barrier-free housing. When comparing two similar dwellings, with the only difference being their accessibility conditions, the 1,007 randomly chosen households that answered the direct survey would pay, on average, $12.5 \%$ more for barrier-free dwellings.

Świeżawska-Ambroziak and Perez (2006) proposed the benefit model to show that many factors may result in an accessible building bringing greater financial gain for the building promoter/owner/user than one that is inaccessible. The model included 1) supplementary profit generated from a broader group of clients, 2) increased building value (the model calculates the percentage difference between the value of an unaltered building and a fully accessible building), 3) subsidies to promote accessibility (various kinds, the value of which depend on the country, type of building, type of promoter/investor, etc.), 4) penalties levied on buildings that are not completely adapted, and 5) reduction of additional costs to serve clients with special needs (for example, an employee from an inaccessible bank visiting clients with disabilities who are unable to come to the bank in person. In this case, not all respective costs would be reduced in line with increased accessibility, because some ill people would still require home visits irrespective of building accessibility). This model does not include social benefits because the conversion of social benefits into direct monetary terms is a very controversial issue.

\subsection{Economic valuation and willingness to pay}

Willingness to pay (WTP) is the maximum amount that consumers will voluntarily pay for a particular good or service, indicating the size of the preference (Tietenberg, 2000). Methods for estimating the amount a person is willing to pay for improvements or alterations to environmental quality include the averting behavior method, hedonic price method, travel cost method, and contingent valuation method (Pearce \& Howarth, 2000). The contingent valuation method (CVM) is a well-known approach to measure a consumer's stated preference for a commodity, attribute, service, or policy (Carson \& Hanemann, 2005), such as a change in environmental amenities. CVM measures an individual's stated WTP for a given subject, attribute, or policy by using survey questions to elicit information about each sampled individual's WTP for implementation of that subject or policy (William, Morey, \& Lodder, 1998).

Hui (1999) used the contingent valuation method to evaluate WTP for better public housing using. Mandell and Wilhelmsson (2011) used the hedonic model to show a positive WTP for sustainable housing features. Greene and Ortúzar (2002) studied WTP for social housing attributes in Chile using the discrete choice model. Simons and Winson-Geideman (2005) also used the CVM to estimate the effects of environmetal contamination on real estate values.

\section{Methodology}

This study used the CVM to estimate the value of accessible barrier-free housing. The CVM is one of the standard approaches for valuing non-market resources, such as environmental quality (Hanemann, Loomis, \& Kanninen, 1991). In CVM, credibility can be obtained by measuring two fundamental indicators: the correct specification of the product or service to be valued (e.g. accessible housing) and the construction of a reliable and neutral valuation scenario (Alonso, 2002).

Therefore, we have created a hypothetical market by directly asking respondents about their WTP for better accessibility features, such as step-free entrances, wider doors and corridors, sufficient space for wheelchairs, accessible toilet facilities, switches located at an easily reachable level, and so on (see Figure 1). The survey questions used in this study are included in the Appendix. 
a)
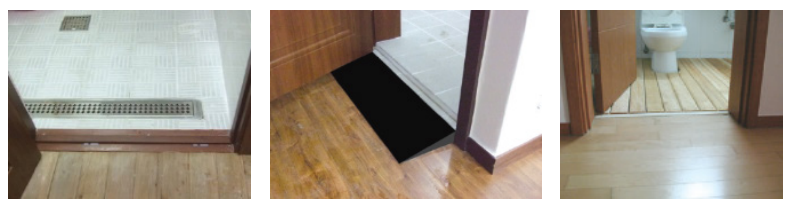

b)
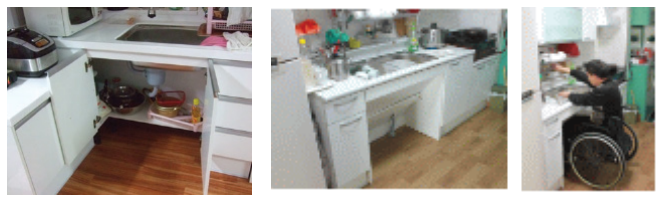

c)

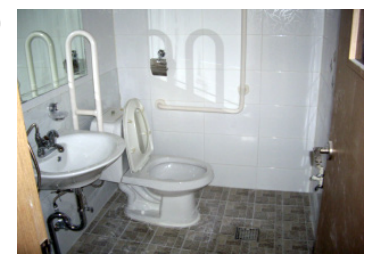

d)

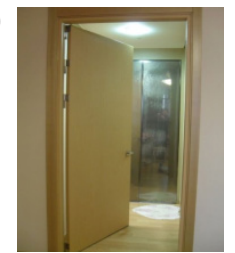

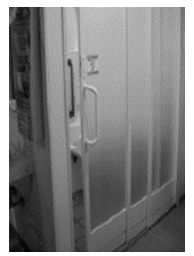

e)

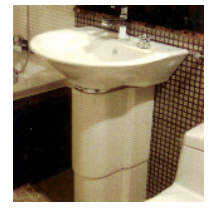

f)

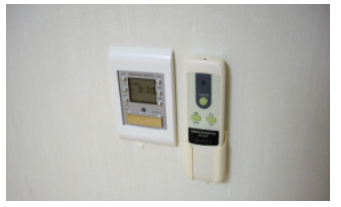

g)

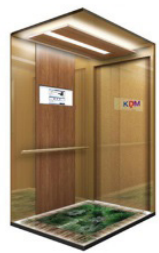

Figure 1. Examples of accessible and barrier-free designs: a - Step-free entrance of bathrooms;

b - Wheelchair-accessible kitchens; c - Grab bars in bathrooms; d - Bathroom doors; e - Height-adjustable wash basin; f - Easy-to-operate light switch; g - Elevator

For the WTP survey, we used two formats. First, we asked whether the respondents would be willing to pay for accessible housing, then we asked an open-ended question in which the respondents stated their maximum WTP for accessible, barrier-free housing. The valuation was directly obtained from the response to the question. We also used the double-bounded dichotomouschoice CVM, proposed by Hanemann (1985) and Carson (1985), in order to obtain a more precise estimation of the respondents' WTP. The double-bounded dichotomous-choice CVM asked the respondents to engage in two rounds of bidding: participants responded first to a dollar amount, then faced a second question involving another dollar amount that was higher or lower depending on the response to the first question (Hanemann et al., 1991). If the respondents answered positively to the first question, that is, they were prepared to pay the presented premium amount for an accessible dwelling, the second question would be whether they would still pay if the amount was increased to a certain level. On the other hand, if they answered negatively, the second question would query their willingness at a lower amount. We asked the absolute amount directly because it was easier to visualize than the premium ratio.
In order to set a bid price, preliminary studies were conducted in Seoul, Korea. To select the survey site, we divided Seoul into four regions (northwest, northeast, southwest, and southeast) and randomly selected five neighborhoods within each region. We determined the WTP amount using an open-ended question in a pilot survey of 120 random subjects from 20 neighborhoods. We proposed four different bid amounts and used the 20th, 40th, 60th, and 80th percentile answer distributions: 10 million KRW (8,360 USD), 20 million KRW (16,720 USD), 50 million KRW (41,790 USD), and 100 million KRW (83,600 USD). The amount in the follow-up question was doubled if the respondents answered "yes" to the first question and halved if they answered "no."

Data were also collected at 14 randomly selected neighborhoods within four regions of Seoul. The respondents were selected by quota sampling, stratified by region, age group, and dwelling type. The survey was administered at the community service centers or senior citizens' center within each neighborhood. A total of 700 people were randomly sampled. We used a self-administered questionnaire for the younger group and conducted personal interviews for the elderly to prevent any misunderstanding of the questionnaire. We distributed almost the same 
number of questionnaire sheets with each of the four bid amounts in the first question and randomly assigned them to the participants.

A double-bounded dichotomous choice questionnaire was used to perform survival analysis on the data. To calculate the mean WTP, the Weibull distribution was chosen for our study. This distribution most frequently provides the best fit for life data and efficient statistics. Descriptive statistics were conducted using SPSS. SAS LIFEREG procedure was used for the survival analysis.

\section{Results}

\subsection{Socio-demographic characteristics}

Of the total 700 cases, 367 respondents were under the age of 65, and 333 respondents were elderly (over
65 years). Regarding gender, $69.6 \%$ of the total respondents were female. Female respondents comprised 64.6\% of the younger group, and $75.1 \%$ of the elderly. In the younger group, 235 respondents $(64.0 \%)$ were in their $40 \mathrm{~s}$ and $50 \mathrm{~s}$. Of the elderly respondents, $44.7 \%$ were over 80 years old. With respect to education, $55.3 \%$ of the younger group had a university degree, and $45.9 \%$ of the elderly had graduated from elementary school. In terms of employment, $29.4 \%$ of the younger group was self-employed, $25.6 \%$ were homemakers, $19.1 \%$ were professionals, and $10.6 \%$ were office workers. Most of the elderly respondents $(82.3 \%)$ were unemployed. Reported monthly household income showed that $24.3 \%$ of the younger group earned from 3 to 4 million KRW (2,507-3,343 USD), and $67.4 \%$ of the elderly earned below 1 million KRW (836 USD) (Table 1).

Table 1. Socio-demographic characteristics of respondents

\begin{tabular}{|c|c|c|c|c|c|c|c|}
\hline \multirow{2}{*}{\multicolumn{2}{|c|}{ Category }} & \multicolumn{2}{|c|}{ Younger } & \multicolumn{2}{|c|}{ Elderly } & \multicolumn{2}{|c|}{ Total } \\
\hline & & $\mathrm{f}$ & $\%$ & $f$ & $\%$ & $f$ & $\%$ \\
\hline \multirow[t]{3}{*}{ Gender } & Male & 130 & 35.4 & 83 & 24.9 & 213 & 30.4 \\
\hline & Female & 237 & 64.6 & 250 & 75.1 & 487 & 69.6 \\
\hline & Total & 367 & 100.0 & 333 & 100.0 & 700 & 100.0 \\
\hline \multirow[t]{9}{*}{ Age } & $20 \mathrm{~s}$ & 26 & 7.1 & 0 & 0.0 & 26 & 3.7 \\
\hline & $30 \mathrm{~s}$ & 73 & 19.9 & 0 & 0.0 & 73 & 10.4 \\
\hline & $40 \mathrm{~s}$ & 116 & 31.6 & 0 & 0.0 & 116 & 16.6 \\
\hline & $50 \mathrm{~s}$ & 119 & 32.4 & 0 & 0.0 & 119 & 17.0 \\
\hline & $60 \mathrm{~s}$ & 33 & 9.0 & 65 & 19.5 & 98 & 14.0 \\
\hline & $70 \mathrm{~s}$ & 0 & 0.0 & 119 & 35.7 & 119 & 17.0 \\
\hline & $80 \mathrm{~s}$ & 0 & 0.0 & 130 & 39.0 & 130 & 18.6 \\
\hline & $90 \mathrm{~s}$ & 0 & 0.0 & 19 & 5.7 & 19 & 2.7 \\
\hline & Total & 367 & 100.0 & 333 & 100.0 & 700 & 100.0 \\
\hline \multirow[t]{7}{*}{ Education } & Uneducated & 1 & 0.3 & 67 & 20.1 & 68 & 9.7 \\
\hline & Elementary school & 5 & 1.4 & 153 & 45.9 & 158 & 22.6 \\
\hline & Middle school & 16 & 4.4 & 55 & 16.5 & 71 & 10.1 \\
\hline & High school & 125 & 34.1 & 41 & 12.3 & 166 & 23.7 \\
\hline & Undergraduate school & 203 & 55.3 & 17 & 5.1 & 220 & 31.4 \\
\hline & Graduate school or higher & 17 & 4.6 & 0 & 0.0 & 17 & 2.4 \\
\hline & Total & 367 & 100.0 & 333 & 100.0 & 700 & 100.0 \\
\hline \multirow[t]{10}{*}{ Job } & Professional & 70 & 19.1 & 6 & 1.8 & 76 & 10.9 \\
\hline & Office worker & 39 & 10.6 & 3 & 0.9 & 42 & 6.0 \\
\hline & Sales and service & 37 & 10.1 & 2 & 0.6 & 39 & 5.6 \\
\hline & Production & 3 & 0.8 & 0 & 0.0 & 3 & 0.4 \\
\hline & Self-employed & 108 & 29.4 & 10 & 3.0 & 118 & 16.9 \\
\hline & Homemaker & 94 & 25.6 & 33 & 9.9 & 127 & 18.1 \\
\hline & Student & 4 & 1.1 & 0 & 0.0 & 4 & 0.6 \\
\hline & Temporary job & 5 & 1.4 & 5 & 1.5 & 10 & 1.4 \\
\hline & Unemployed & 7 & 1.9 & 274 & 82.3 & 281 & 40.1 \\
\hline & Total & 367 & 100.0 & 333 & 100.0 & 700 & 100.0 \\
\hline \multirow{9}{*}{$\begin{array}{l}\text { Monthly } \\
\text { household } \\
\text { income }\end{array}$} & Less than 1 million KRW (836 USD) & 17 & 4.6 & 224 & 67.3 & 241 & 34.4 \\
\hline & 1-1.99 million KRW (836-1,671 USD) & 48 & 13.1 & 54 & 16.2 & 102 & 14.6 \\
\hline & 2-2.99 million KRW $(1,672-2,506$ USD) & 79 & 21.5 & 28 & 8.4 & 107 & 15.3 \\
\hline & 3-3.99 million KRW $(2,507-3,342$ USD) & 89 & 24.3 & 20 & 6.0 & 109 & 15.6 \\
\hline & 4-4.99 million KRW $(3,343-4,178$ USD) & 58 & 15.8 & 3 & 0.9 & 61 & 8.7 \\
\hline & 5-6.99 million KRW $(4,179-5,849$ USD) & 48 & 13.1 & 2 & 0.6 & 50 & 7.1 \\
\hline & 7-9.99 million KRW $(5,850-8,359$ USD) & 24 & 6.5 & 1 & 0.3 & 25 & 3.6 \\
\hline & 10 million or more KRW $(8,360$ USD - ) & 4 & 1.1 & 1 & 0.3 & 5 & 0.7 \\
\hline & Total & 367 & 100.0 & 333 & 100.0 & 700 & 100.0 \\
\hline
\end{tabular}




\subsection{Housing characteristics}

Respondents' housing characteristics are shown in Table 2. Regarding housing type, most of respondents (65.1\%) lived in an apartment, and the remainder in single-family houses or other housing types $(25.0 \%$ and $9.9 \%$, respectively). Medium- and large-sized apartments were inhabited by $40.9 \%$ of the younger group, and $40.5 \%$ of the elderly. Homeownership was high, with $65.1 \%$ of the younger group, and $73.0 \%$ of the elderly owning a house. Homeownership is the most common form of house tenure in Korea. The average homeownership rate was $58 \%$ according to the 2007 report from the Korean Ministry of Land, Transport and Maritime Affairs. The percentage of elders who are homeowners is even higher, at about $72.9 \%$. Unit sizes of $83-108 \mathrm{~m}^{2}$ were predominant $(30.7 \%)$.

\subsection{Results of the open-ended model}

Of the total respondents, 375 (53.6\%) stated that they were willing to pay for accessible rather than conventional housing (see Table 3 ). There was a statistically significant differ- ence in WTP between the elderly and the younger group. The younger group $(77.9 \%)$ showed a higher tendency to pay the premium amount compared to the elderly (26.7\%).

The distribution of the WTP amount from the openended format is shown in Table 4. It was statistically significant. Most of the respondents (76.4\%) stated that they were willing to pay under 30 million KRW (25,080 USD). For the younger group, the top-ranked WTP amount was 10-30 million KRW (8,360-25,080 USD) at 50.4\%, and the second was less than 10 million KRW (USD 8,360) at $24.4 \%$. For the elderly, the top-ranked WTP amount was under 10 million KRW (USD 8,360) at 52.8\%, and the second was 10-30 million KRW (8,360-25,080 USD) at 29.2\%.

The mean WTP amounts that respondents answered in the open-ended format are shown in Table 5. The total mean WTP amount was 27.3 million KRW $(23,742$ USD). The mean value from the younger group (28.3 million KRW or 24,495 USD) was higher than that of the elderly (23.7 million KRW or 21,736 USD). However, the difference in the WTP mean amount was not statistically significant.

Table 2. Respondents' housing characteristics

\begin{tabular}{|c|c|c|c|c|c|c|c|}
\hline \multirow{2}{*}{\multicolumn{2}{|c|}{ Category }} & \multicolumn{2}{|c|}{ Younger } & \multicolumn{2}{|c|}{ Elderly } & \multicolumn{2}{|c|}{ Total } \\
\hline & & $\mathrm{f}$ & $\%$ & $\mathrm{f}$ & $\%$ & $\mathrm{f}$ & $\%$ \\
\hline \multirow{5}{*}{$\begin{array}{l}\text { Housing } \\
\text { type }\end{array}$} & Single-family house & 90 & 24.5 & 85 & 25.5 & 175 & 25.0 \\
\hline & Small apartment & 90 & 24.5 & 81 & 24.3 & 171 & 24.4 \\
\hline & $\begin{array}{l}\text { Medium/large-sized } \\
\text { apartment }\end{array}$ & 150 & 40.9 & 135 & 40.5 & 285 & 40.7 \\
\hline & Other & 37 & 10.1 & 32 & 9.6 & 69 & 9.9 \\
\hline & Total & 367 & 100.0 & 333 & 100.0 & 700 & 100.0 \\
\hline \multirow[t]{5}{*}{ Tenure type } & Own & 239 & 65.1 & 243 & 73.0 & 482 & 68.9 \\
\hline & Jeonse rent & 105 & 28.6 & 74 & 22.2 & 179 & 25.6 \\
\hline & Monthly rent & 15 & 4.1 & 8 & 2.4 & 23 & 3.3 \\
\hline & Other & 8 & 2.2 & 8 & 2.4 & 16 & 2.3 \\
\hline & Total & 367 & 100.0 & 333 & 100.0 & 700 & 100.0 \\
\hline \multirow{6}{*}{$\begin{array}{l}\text { Size of unit } \\
\left(\mathrm{m}^{2}\right)\end{array}$} & Under 59 & 84 & 22.9 & 65 & 19.5 & 149 & 21.3 \\
\hline & $60-82$ & 71 & 19.3 & 73 & 21.9 & 144 & 20.6 \\
\hline & $83-108$ & 126 & 34.3 & 89 & 26.7 & 215 & 30.7 \\
\hline & $109-148$ & 67 & 18.3 & 82 & 24.6 & 149 & 21.3 \\
\hline & Over 149 & 19 & 5.2 & 24 & 7.2 & 43 & 6.1 \\
\hline & Total & 367 & 100.0 & 333 & 100.0 & 700 & 100.0 \\
\hline
\end{tabular}

Table 3. WTP responses in open-ended format

\begin{tabular}{|c|c|c|c|c|c|c|}
\hline \multirow{2}{*}{ Category } & \multicolumn{2}{|c|}{ Younger } & \multicolumn{2}{|c|}{ Elderly } & \multicolumn{2}{|c|}{ Total } \\
\hline & $\mathrm{F}$ & $\%$ & $\mathrm{f}$ & $\%$ & $\mathrm{f}$ & $\%$ \\
\hline Yes & 286 & 77.9 & 89 & 26.7 & 375 & 53.6 \\
\hline No & 81 & 22.1 & 244 & 73.3 & 325 & 46.4 \\
\hline Total & 367 & 100.0 & 333 & 100.0 & 700 & 100.0 \\
\hline
\end{tabular}

Note: $\chi^{2}=184.024, \mathrm{p}<0.001$ 
Table 4. Distribution of the WTP amount from open-ended format questionnaire

\begin{tabular}{|c|c|c|c|c|c|c|}
\hline \multirow{2}{*}{ Category } & \multicolumn{2}{|c|}{ Younger } & \multicolumn{2}{|c|}{ Elderly } & \multicolumn{2}{|c|}{ Total } \\
\hline & $\mathrm{f}$ & $\%$ & $\mathrm{f}$ & $\%$ & $\mathrm{f}$ & $\%$ \\
\hline Under 10 & 62 & 24.4 & 38 & 52.8 & 100 & 30.7 \\
\hline $10-30$ & 128 & 50.4 & 21 & 29.2 & 149 & 45.7 \\
\hline $30-50$ & 19 & 7.5 & 5 & 6.9 & 24 & 7.4 \\
\hline $50-100$ & 21 & 8.3 & 2 & 2.8 & 23 & 7.1 \\
\hline Over 100 & 24 & 9.4 & 6 & 8.3 & 30 & 9.2 \\
\hline Total & 254 & 100.0 & 72 & 100.0 & 326 & 100.0 \\
\hline
\end{tabular}

Note: Unit: million KRW, $\chi^{2}=22.742, \mathrm{p}<0.001$.

Table 5. WTP amount in open-ended format

\begin{tabular}{|l|c|c|c|c|c|}
\hline \multicolumn{1}{|c|}{ Category } & $\mathrm{N}$ & Mean & Std. Dev. & Min. & Max. \\
\hline Younger & 254 & 2,832 & $5,404.1$ & 10 & 10 \\
\hline Elderly & 72 & 2,367 & $4,994.9$ & 10,000 & 25,000 \\
\hline Total & 326 & 2,729 & $5,312.4$ & 10 & 50,000 \\
\hline
\end{tabular}

Note: Unit: 10,000 KRW.

\subsection{Results from the double-referendum model through survival analysis}

The distribution of WTP responses for dichotomous choices is shown in Table 6. The rate of "yes" answers decreases as the cost shown to the respondents increases. In Table 5, the "No-No" column refers to the percentage of respondents refusing to pay either bid. Of the 697 total respondents, $37.4 \%$ accepted at least one of the suggested bid prices, while $62.6 \%$ said that they had no WTP for accessible, barrier-free housing. There was a statistically significant difference in WTP between the elderly and the younger group. Among the 366 younger respond- ents, $40.0 \%$ had no WTP for either of the bid amounts, while $60.0 \%$ indicated a willingness to pay some premium amount. However, most of the elderly respondents (87.0\%) had no WTP for either of the bid values.

Table 7 shows the mean extra amount that respondents would pay for accessible, barrier-free housing compared with conventional housing. The value estimated from the respondents who had WTP was 84.8 million KRW (70,893 USD).

The double-referendum format generated larger WTP estimates than the open-ended format. The mean WTP amount estimated from the double-referendum format was almost three times higher. This result is similar to

Table 6. Answers on WTP from double referendum format

\begin{tabular}{|c|c|c|c|c|c|c|}
\hline \multirow{2}{*}{ Category } & \multirow{2}{*}{$\begin{array}{l}\text { 1st bid amount } \\
\text { (million KRW) }\end{array}$} & \multirow{2}{*}{$\mathrm{N}$} & \multicolumn{4}{|c|}{ WTP (\%) } \\
\hline & & & Yes-Yes & Yes-No & No-Yes & No-No \\
\hline \multirow[t]{5}{*}{ Younger } & 10 & 97 & 29.9 & 25.8 & 15.5 & 28.9 \\
\hline & 20 & 94 & 18.1 & 18.1 & 34.0 & 29.8 \\
\hline & 50 & 85 & 10.6 & 14.1 & 30.6 & 44.7 \\
\hline & 100 & 90 & 6.7 & 12.2 & 21.1 & 60.0 \\
\hline & Total & 366 & 16.7 & 17.8 & 25.1 & 40.0 \\
\hline \multirow[t]{5}{*}{ Elderly } & 10 & 82 & 13.4 & 4.9 & 3.7 & 78.0 \\
\hline & 20 & 78 & 6.4 & 6.4 & 5.1 & 82.1 \\
\hline & 50 & 84 & 2.4 & 2.4 & 2.4 & 92.9 \\
\hline & 100 & 87 & 2.3 & 1.1 & 2.3 & 94.3 \\
\hline & Total & 331 & 6.0 & 3.6 & 3.3 & 87.0 \\
\hline \multirow[t]{5}{*}{ Both } & 10 & 179 & 22.3 & 16.2 & 10.1 & 51.4 \\
\hline & 20 & 172 & 12.8 & 12.8 & 20.9 & 53.5 \\
\hline & 50 & 169 & 6.5 & 8.3 & 16.6 & 68.6 \\
\hline & 100 & 177 & 4.5 & 6.8 & 11.9 & 76.8 \\
\hline & Total & 697 & 11.6 & 11.0 & 14.8 & 62.6 \\
\hline
\end{tabular}

Note: $\chi^{2}=164.544, \mathrm{p}<0.001$. 
other researches that show that mean WTP estimated from dichotomous choice question is 1.4 to 2.5 times larger than mean WTP estimated from an open-ended question (Bishop, Heberlein, \& Kealy, 1983; Kealy \& Turner, 1993; Kriström, 1993; Ready, Buzby, \& Hu, 1996).

As seen in Table 7, the mean values of WTP differ significantly according to age group, gender, housing type, size of unit, or tenure type. The elderly group showed a greater WTP than the younger group. The mean WTP value estimated for the younger group was 71.0 million KRW (59,356 USD), and for the respective elderly group, 130.4 million KRW (109,014 USD). The higher mean WTP indicates that the elderly group values accessible housing more than the younger one, and their demands for accessible housing could be higher. Furthermore, the elderly group showed a wide distribution of mean WTP, with a range from a lower bound of 99.9 million KRW (83,516 USD) to an upper bound of 170.2 million KRW (142,286 USD) (see Figure 2). This result indicates that the degree of demands for accessible housing from the elderly group varies widely in comparison with the younger group. The elderly face different physical conditions, and thus their demands are various. In addition, their conditions to afford accessible housing vary because some of the older adults could belong to high economic groups due to savings, pensions, or homeownership, even if they do not have a job or have low to little monthly income.

In terms of gender, male respondents showed higher mean WTP than females. The value estimated for male respondents who had WTP was 89.4 million KRW (74,738 USD), while the value estimated for female respondents with WTP was 78.4 million KRW (65,542 USD).

Table 7. The WTP amount according to demographic characteristics

\begin{tabular}{|c|c|c|c|c|}
\hline & Category & Mean payment & $95 \%$ & rval \\
\hline Total & & $8,480.55$ & $7,707.24$ & $9,331.45$ \\
\hline Age group & Younger & $7,103.01$ & $6,411.62$ & $7,868.96$ \\
\hline & Elderly & $13,038.89$ & $9,988.24$ & $17,021.27$ \\
\hline Gender & Male & $8,942.11$ & $7,603.76$ & $10,516.01$ \\
\hline & Female & $7,837.29$ & $6,962.13$ & $8,822.46$ \\
\hline Housing type & Single-family house and others & $7,212.19$ & $6,131.03$ & $8,483.99$ \\
\hline & Apartment & $8,976.23$ & $7,964.44$ & $10,116.56$ \\
\hline Size of unit & Small & $8,529.27$ & $7,345.46$ & $9,903.87$ \\
\hline & Medium and large & $9,888.51$ & $8,720.65$ & $11,212.78$ \\
\hline Tenure type & Rent & $4,828.62$ & $4,032.57$ & $5,781.82$ \\
\hline & Owned & $9,345.00$ & $8,291.39$ & $10,532.49$ \\
\hline
\end{tabular}

Note: Unit: 10,000 KRW.

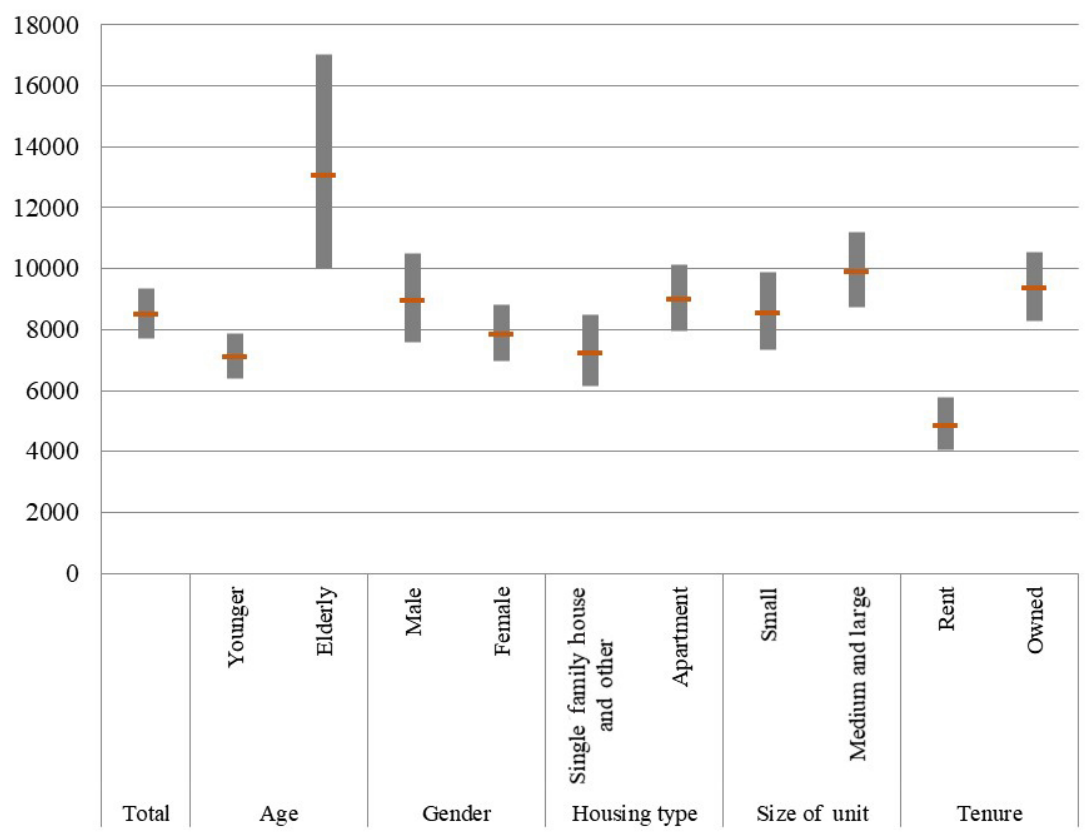

Figure 2. WTP amount according to demographic characteristics 
With respect to housing type, respondents who lived in apartments showed greater WTP than those living in singlefamily houses or other housing types. The value estimated for respondents living in apartments was 89.8 million KRW (75,073 USD). For respondents with WTP who lived in single-family housing, it was 72.1 million KRW (60,276 USD).

Looking at unit size, respondents who lived in medium or large houses showed higher WTP than those living in small houses (less than $82 \mathrm{~m}^{2}$ ). The value estimated for respondents who lived in small houses was 85.3 million KRW (71,311 USD), while for those living in medium or large houses, it was 98.9 million KRW (82,680 USD).

In terms of tenure type, respondents who owned a house showed greater WTP than those living in rented housing. The value estimated for respondents owning a house was 93.5 million KRW (78,166 USD). For those who lived in rented housing, it was 48.3 million KRW (40,379 USD).

Comprehensively, economical people, such as men, apartment dwellers, medium- and large-scale housing residents, and home owners showed that they are willing to pay more. However, the elderly's willingness to pay was higher regardless of economic power. It can be concluded that the elderly may feel more uncomfortable in an inaccessible environment and therefore their demand for a barrier-free environment is high, even if they must pay for it.

Table 8 shows the mean extra amount that respondents would pay for accessible, barrier-free housing according to the housing type in which they currently live. Respondents living in medium- and large-sized apartments showed more WTP than those in a small apartment or singlefamily house. The value estimated for those who lived in medium- and large-sized apartments was 91.9 million KRW (76,828 USD). For respondents who lived in small apartments, it was 85.3 million KRW (71,311 USD). From single-family houses, with multi-family houses included, it was 79.6 million KRW (66,546 USD). Among respondents living in single-family houses, and medium- and largesized apartments, the elderly group showed greater WTP than the younger group. However, among respondents living in small apartments, the younger group showed greater WTP.

In the elderly group, there was a clearly wider distribution of mean WTP regardless of housing type in comparison with the younger group (see Figure 3 ). The distribution

Table 8. WTP according to housing type

\begin{tabular}{|l|c|c|c|c|}
\hline \multicolumn{2}{|c|}{ Category } & Mean payment & \multicolumn{2}{c|}{$95 \%$ confidence interval } \\
\hline \multirow{4}{*}{ Single-family house } & Both & $7,956.60$ & $6,506.77$ & $9,729.48$ \\
\cline { 2 - 5 } & Younger & $4,916.60$ & $3,881.35$ & $6,227.98$ \\
\cline { 2 - 5 } & Elderly & $17,781.80$ & $9,947.17$ & $31,787.17$ \\
\hline \multirow{3}{*}{ Small apartment } & Both & $8,530.03$ & $7,047.71$ & $10,324.13$ \\
\cline { 2 - 5 } & Younger & $7,575.34$ & $6,175.24$ & $9,292.88$ \\
\cline { 2 - 5 } & Elderly & $3,564.13$ & $1,798.04$ & $7,064.95$ \\
\hline \multirow{2}{*}{$\begin{array}{l}\text { Medium- and large-sized } \\
\text { apartment }\end{array}$} & Both & $9,190.77$ & $7,884.40$ & $10,713.58$ \\
\cline { 2 - 5 } & Younger & $7,762.66$ & $6,568.72$ & $9,173.61$ \\
\cline { 2 - 5 } & Elderly & $12,571.05$ & $8,570.59$ & $18,438.79$ \\
\hline
\end{tabular}

Note: Unit: 10,000 KRW.

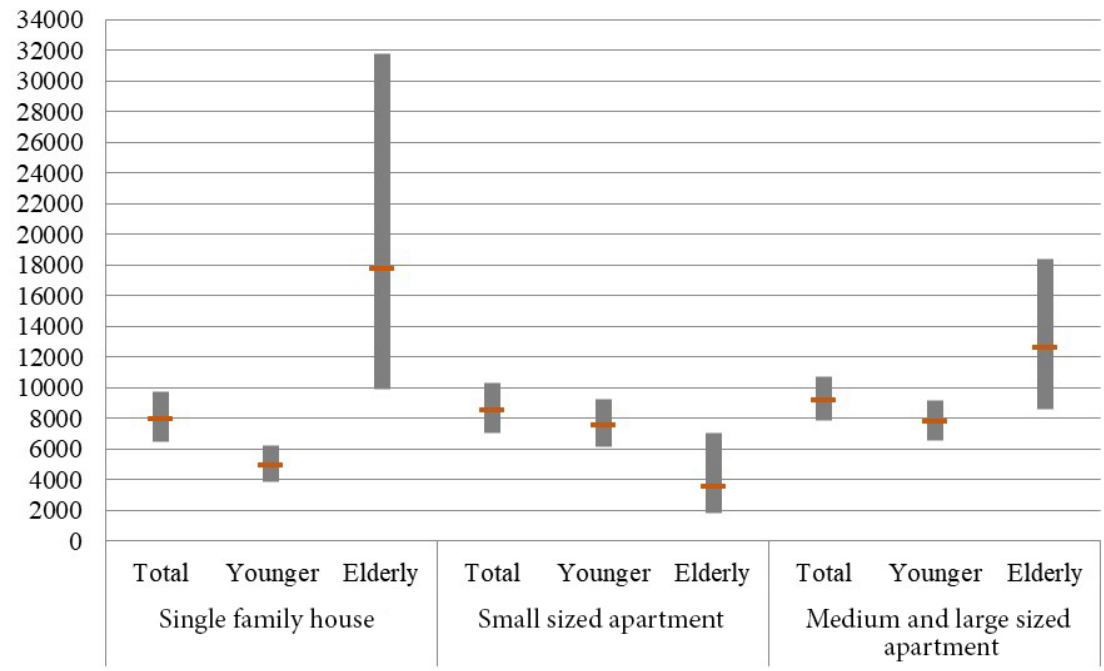

Figure 3. WTP according to housing type 
of mean WTP of elders living in single-family houses was the widest followed by medium- and large-sized apartment. In single-family houses, housing conditions including house type, size, and degree of accessibility is more diverse when compared to apartments. Thus, elders living in single family houses might experience more inconvenience than those who live in apartments, and therefore their needs can have larger variance than apartment residents.

We performed an analysis to identify the factors influencing the WTP (Table 9). Among the factors analyzed, awareness on the importance of accessible and barrier-free design, gender, monthly household income, education level, and home ownership showed a statistically significant influence on WTP. Respondents with a higher economic status showed greater WTP in this study. Education level is an important proxy of social economic status, thus, the results might actually be related to economic status (M. Kim, Lee, J. Kim, \& Joo, 2011). Home ownership could also be related to economic status. Housing type and unit size did not show statistically significant influence on WTP, even though these factors are also related to economic status.

\section{Discussion}

As population aging increases due to higher-quality lifestyle and innovative medical care, accessible housing is becoming crucial so senior residents can live autonomously within their own homes. However, most of housing stocks are currently considered inaccessible for residents with functional limitations. These residents increase the demand for affordable and accessible housing. This study investigates whether there is willingness to pay more for accessible housing. For that, the costs for accessible housing were estimated using the CVM. The results of this study provide us with various insights in terms of research and policies. The research analysis shows considerable values for the assessment of market potential of accessible housing and provides a preliminary indication of the value of accessible housing to housing providers.

WTP for accessible housing varied according to the question format. In the open-ended question, $54.1 \%$ of respondents indicated WTP for accessible housing. However, in a bidding situation, fewer respondents indicated WTP (37.4\%). Although the frequency of individuals with WTP may be low, this study suggests that a considerable amount of WTP exists. In addition, this study analyzed the related values for accessible housing. When respondents indicate a WTP, the respective premium estimated using LIFEREG analysis is considerable compared to the cost of accessible housing. According to our study, the range people are willing to pay as an extra for accessible features is from $6.1 \%$ (open-ended model) to $19.0 \%$ (double-referendum model) more than the average house price in Seoul, Korea. It is a higher amount than the required to achieve accessibility.

The elderly, in particular, indicated a higher WTP, and the mean amount is higher than the younger group. The implication is that elderly, high-income individuals would be willing to pay for an accessible house. Considering that the elderly population is commonly increasing in developed countries, the higher the WTP of the elderly, the more feasible the possibility of accessible housing as an alternative in the housing market.

Mass housing construction and monolithic structures failed to provide accessible dwellings for people especially for the elderly and the disabled (Choi, 2003). Most housing research has focused on younger home-

Table 9. Results of survival analysis

\begin{tabular}{|c|c|c|c|c|c|}
\hline \multirow{3}{*}{$\begin{array}{l}\text { Parameter } \\
\text { Intercept }\end{array}$} & \multicolumn{5}{|c|}{ Total } \\
\hline & \multirow{2}{*}{$\frac{\text { Estimate }}{4.6402}$} & \multicolumn{2}{|c|}{ 95\% confidence limits } & \multirow{2}{*}{$\begin{array}{c}\text { Chi-Square } \\
30.11\end{array}$} & \multirow{2}{*}{$\frac{\operatorname{Pr}>\text { Chi-Square }}{<0.0001}$} \\
\hline & & 2.9829 & 6.2975 & & \\
\hline Imp & 0.4118 & 0.2438 & 0.5799 & 23.07 & $<0.0001$ \\
\hline h_satisfy & 0.0159 & -0.0887 & 0.1206 & 0.09 & 0.7654 \\
\hline Sex & -0.3159 & -0.5978 & -0.0339 & 4.82 & 0.0281 \\
\hline Age & -0.0056 & -0.0203 & 0.009 & 0.57 & 0.45 \\
\hline Jo & -0.0897 & -0.4209 & 0.2415 & 0.28 & 0.5956 \\
\hline Edu & 0.1659 & 0.0151 & 0.3167 & 4.65 & 0.031 \\
\hline income & 0.1848 & 0.0941 & 0.2754 & 15.96 & $<0.0001$ \\
\hline h_t & 0.0934 & -0.161 & 0.3477 & 0.52 & 0.4719 \\
\hline h_size & -0.0335 & -0.1544 & 0.0874 & 0.3 & 0.587 \\
\hline ho_group & 0.389 & 0.0861 & 0.6919 & 6.34 & 0.0118 \\
\hline disorder & 0.0751 & -0.0404 & 0.1907 & 1.62 & 0.2025 \\
\hline dis_fam & 0.3221 & -0.0215 & 0.6657 & 3.38 & 0.0661 \\
\hline Elderly & -0.096 & -0.5858 & 0.3938 & 0.15 & 0.7008 \\
\hline Log likelihood & & & -542.428 & & \\
\hline
\end{tabular}


buyers. However, housing preferences need to consider the demand for a greater range of housing alternatives for seniors (Gibler \& Taltavull, 2010). Accessible housing can help many elderly and disabled people to stay in their own homes, and it provides intangible benefits such as extra comfort and security (Alonso, 2002). The results of this study support that accessible housing can be an important housing-choice option so that the elderly and disabled can foster and support independent living. Moreover, the demand is more apparent due to the current population aging.

Despite the demand for accessible housing, the housing market currently lacks such options. It is necessary to provide accessible housing for those willing to pay more. With regard to housing supply, accessible housing may be used as a marketing strategy, especially for multifamily housing complexes. Additionally, housing policies could be leveraged to require accessible housing options. In highly populated cities such as Seoul, new construction to existing housing complexes is limited by several housing policies and regulations, and therefore only a few projects have been initiated. Accessible housing may be beneficial for housing-vulnerable people like the elderly, and offers a sustainable housing option as the aging portion of the population increases. The results of this study reflect a need for policies or services in the housing market that meet the demand for accessible housing.

As it is not feasible to supply every new house with accessible features, it is important to find ways to modify or remodel existing housing stock. Reliable and tangible information should be used to promote accessible housing in both the public and private sectors to help people better understand accessible housing. It is possible to provide a support service to help modification or alteration of existing housing when there is a demand. Especially for the elderly living in single-family house, the support for remodeling will be very helpful, since their housing conditions, including house type, housing size, and the degree of accessibility, are more diverse when compared to apartments.

As previous studies have reported, in contrast with hypothetical environments, people may act differently if purchasing housing against their willingness (Chan, Yiu, Baldwin, \& Lee, 2009). Although results of CVM have been criticized because of its limitations in identifying differences between WTP and reality, it is particularly useful to assess the monetary values of non-market goods, services, environmental features, or parameters for policies (Chan et al., 2009; Kim et al., 2011).

While the double referendum question format, which references price from the previous valuation, has a negative anchoring effect, it also has apparent positive effects. For example, once participants have experienced valuation, they have another chance to reconsider the amount they are willing to pay (Alonso, 2002). As mentioned earlier, the CV estimation is a typical method of value estima- tion. However, if respondents do not fully understand the environmental features or attribute characteristics they are asked about, they are less likely to accurately estimate the amount they would be willing to pay for those features. In order to provide more tangible information to participants, the accessible housing features were presented with both pictures and descriptions. Although the study was limited by this inherent weakness in the methodology, the use of tangible information about accessible housing design, as well as on-site interviews with elderly participants may have improved the validity of results. Consistent with previous findings, this study found that WTP for accessible housing exceeds the actual costs required to build such housing (Alonso, 2002).

\section{Conclusions}

This study found that some elderly people wanting accessible housing indicated a WTP value higher than the cost of implementing barrier-free attributes. In other words, the value of accessible housing can exceed its cost. This finding is meaningful because it highlights that the amount of willingness to pay for people who demand accessible housing is more than the cost of accessible housing. At bid condition, the younger group was more willing to pay for accessible housing than the elderly group, however, the amount they were willing to pay was less than that expressed by the elderly group. This result indicates a more robust demand for accessible housing by the elderly group than by the younger group. Since accessible standards can be efficient and cost- effective options if they are applied at the planning stages of house construction, the housing market needs to incorporate accessible housing options as a more sustainable marketing option. We can conclude that Korean consumers are ready to pay a significant premium for accessible housing features as the aging population significantly increases.

Due to various factors affecting housing costs, this study is also limited in its applicability to other countries. However, the aging population is increasing worldwide, and considering the favorability of living independently, accessible housing characteristics may be important in housing markets outside East Asia. The result of this study helps to determine the degree of accessibility and the extra cost individuals are willing to pay for accessible housing according to age group, gender, housing type, size of unit, and tenure type in Korea. Consequently, policymakers, planners, designers, and developers should consider accessible design features and adopt accessible housing design or construction characteristics in response to the population's changing needs.

\section{Acknowledgements}

This work was supported by the National Research Foundation of Korea (NRF) grant funded by the Korea government (NRF-2011-0014746) (NRF-2016R1A2B4014631). 


\section{References}

Alonso, F. (2002). The benefits of building barrier-free: a contingent valuation of accessibility as an attribute of housing. European Journal of Housing Policy, 2(1), 25-44. https://doi.org/10.1080/14616710110120577

Bishop, R., Heberlein, T., \& Kealy, M. (1983). Contingent valuation of environmental assets: comparison with a stimulated market. Natural Resources Journal, 23, 619-633.

Carson, R. (1985). Three essays on contingent valuation (welfare economics, non-market goods, water quality) (Ph.D. dissertation). Department of agricultural economics and resource economics, University of California, Berkeley.

Carson, R. T., \& Hanemann, W. M. (2005). Contingent valuation. In K. G. Mäler \& J. R. Vincent (Eds.), Handbook of environmental economics (pp. 821-936). Amsterdam: Elsevier. https:// doi.org/10.1016/S1574-0099(05)02017-6

Chan, E., Yiu, C. Y., Baldwin, A., \& Lee, G. (2009). Value of buildings with design features for healthy living: a contingent valuation approach. Facilities, 27(5/6), 229-249. https://doi.org/10.1108/02632770910944952

Choi, S. (2003). Problems of housing polices for elderly Koreans and directions for improvement of the problems. Architecture, 47(6), 16-20.

Chollet, D. (1979). A cost-benefit analysis of accessibility. Department of Housing and Urban Development, Office of Policy Development and Research.

Demirkan, H. (1991). Some criteria for designing interiors for the Turkish disabled and elderly. In 3rd Ergonomics Congress Proceedings (pp. 499-509), MPM, Ankara.

Demirkan, H. (2007). Housing for the aging population. European Review of Aging and Physical Activity, 4(1), 33-38. https://doi.org/10.1007/s11556-007-0016-Z

Dunn, P. A. (1988). The impact of housing upon the independent living outcomes of individuals with disabilities (Unpublished doctoral dissertation). The F. Heller Graduate School for Advanced Studies in Social Welfare, Brandeis University, Waltham, Massachusetts.

Fänge, A., \& Iwarsson, S. (2005). Changes in ADL dependence and aspects of usability following housing adaptation - a longitudinal perspective. The American Journal of Occupational Therapy, 59(3), 296-304. https://doi.org/10.5014/ajot.59.3.296

Frisch, J. (1998). The benefits of accessible buildings and transport. Physical Disability Council of NSW, Sydney, NSW. Retrieved from www.pdcnsw.org.au/Access.pdf

Gaia, S. (2008). The costs of accessibility solution application in restoring old building: PALACIO LUZ - CURITIBA - BRAZIL. In Proceedings of CIB W084, International Meeting on Building comfortable and livable environments for all (pp. 168175), Georgia Tech University, Atlanta, USA.

Gibler, K. M., \& Taltavull, P. (2010). Using preference for international retires housing market segmentation. Journal of Property Research, 27(3), 221-237.

https://doi.org/10.1080/09599916.2010.518403

Greene, M., \& Ortúzar, J. (2002). Willingness to pay for social housing attributes: a case study from Chile. International Planning Studies, 7(1), 55-87.

https://doi.org/10.1080/13563470220112607

Hanemann, M. (1985). Some issues in continuous and discrete response contingent valuation studies. Northeastern Journal of Agricultural Economics, 14(1), 5-13.

https://doi.org/10.1017/S0899367X00000702
Hanemann, M., Loomis, J., \& Kanninen, B. (1991). Statistical efficiency of double-bounded dichotomous choice contingent valuation. American Journal of Agricultural Economics, 73(4), 1255-1263. https://doi.org/10.2307/1242453

Hui, E. C. M. (1999). Willingness to pay for better housing in Hong Kong: theory and evidence (of dwelling space). Urban Studies, 36(2), 289-304.

https://doi.org/10.1080/0042098993619

Iwarsson, S., \& Slaug, B. (2010). Housing enabler: a method for rating/screening and analysing accessibility problems in housing (2nd ed.). Lund: Veten \& Skapen HB \& Slaug Enabling Development.

Kealy, J., \& Turner, W. (1993). A test of the equality of closedended and open-ended contingent valuations. American Journal of Agricultural Economics, 75(2), 321-331.

https://doi.org/10.2307/1242916

Kim, M., Lee, K., Kim, J., \& Joo, J. (2011). Willingness to pay for hospice care using the contingent valuation method. Yonsei Medicine Journal, 52(3), 510-521.

https://doi.org/10.3349/ymj.2011.52.3.510

Kriström, B. (1993). Comparing continuous and discrete contingent valuation questions. Environmental and Resource Economics, 3(1), 63-71. https://doi.org/10.1007/BF00338320

Lawlor, D., \& Thomas, M. (2008). Residential design for aging in place. Hoboken, New Jersey: John Wiley \& Sons, Inc.

Lee, S. (2014). Cost analysis on application of accessible design features for the elderly housing. Journal of the Architectural Institute of Korea, 30(1), 53-60.

https://doi.org/10.7842/kigas.2014.18.3.53

Lien, L., Steggell, C., Slaug, B., \& Iwarsson, S. (2016). Assessment and analysis of housing accessibility: adapting the environmental component of the housing enabler to United States applications. Journal of Housing and the Built Environment, 31(3), 565-580. https://doi.org/10.1007/s10901-015-9475-0

Mandell, S., \& Wilhelmsson, M. (2011). Willingness to pay for sustainable housing. Journal of Housing Research, 20(1), 35-52.

McFadden, E., \& Lucio, J. (2014). Aging in (privatized) places: subsidized housing policy and seniors. Journal of Housing for the Elderly, 28, 268-287.

https://doi.org/10.1080/02763893.2014.930364

Memken, J., \& Earley, N (2007). Accessible housing availability for the growing U.S. elderly population. Housing and Society, 34(1), 101-115. https://doi.org/10.1080/08882746.2007.11430547

Pearce, D. W., \& Howarth, A. (2000). Technical report on methodology: cost benefit analysis and policy responses. RIVM.

Pirkl, J. (1994). Transgenerational design: products for an aging population. New York: Van Nostrand Reinhold.

Ready, C., Buzby, J., \& Hu, D. (1996) Differences between continuous and discrete contingent value estimates. Land Economics, 72(3), 397-411. https://doi.org/10.2307/3147205

Ratzka, A. (1994, June). A brief survey of studies on costs and benefits of non-handicapping environments. Paper presented at the International Congress on Accessibility in Rio de Janeiro, Brazil. Retrieved from www.independentliving.org/cib/ cibrio94access.html

Sagdic, Y., \& Demirkan, H. (2000). A design decision support system model for the wet space renovation of elderly people's residences. Architectural Science Review, 43, 125-132. https://doi.org/10.1080/00038628.2000.9696895

Schroeder, S., \& Steinfeld, E. (1979). The estimated cost of accessible buildings. U.S. Department of Housing and Urban Development, Washington, D.C. 
Simons, R., \& Winson-Geideman, K. (2005). Determining market perceptions on contamination of residential property buyers using contingent valuation surveys. Journal of Real Estate Research, 27(2), 193-220.

Świeżawska-Ambroziak, K., \& Perez, J. (2006). Economical benefits of the design for all (POLIS project). In POLIS International Conference Proceedings (pp. 67-72), Bruges, Belgium. Retrieved from http://citeseerx.ist.psu.edu/viewdoc/downloa $\mathrm{d}$ ?doi=10.1.1.104.6998\&rep=rep1\&type $=$ pdf
Tietenberg, T. (2000). Environmental and natural resource economics. Addison-Wesley Longman.

William, S. B., Morey, E. R., \& Lodder, T. S. (1998). Using contingent valuation to estimate a neighborhood's willingness to pay to preserve undeveloped land. Urban Studies, 35(4), 715-727. https://doi.org/10.1080/0042098984718

\section{Appendix}

Survey provided to study participants

Accessible housing provides better accessibility such as step-free entrances, wider doors and corridors, sufficient space for wheelchairs, accessible toilet facilities, switches located at an easily reachable level, and so on.

Q1. If an accessible housing is provided, are you willing to pay extra for the purchase?
1) Yes
2) No

Q2. If you pay extra for the purchase, please indicate the maximum amount you are willing to pay.

(...............................................) won

Q3. If you are willing to pay extra for the purchase, are you willing to pay (first suggested amount) won more?
1) Yes (go to Q3-1)
2) No (go to Q3-2)

Q3-1. Then, are you willing to pay (twice the first suggested amount) won more for the purchase?
1) Yes
2) No

Q3-2. Then, are you willing to pay (half of first suggested amount) won more for the purchase?
1) Yes
2) No

Q4. Are you willing to renovate the house for better accessibility?
1) Yes
2) No

Q5. If you are renovating a house for better accessibility, please indicate the maximum amount you are willing to pay. ..) won

Q6. If you are renovating a house for better accessibility, are you willing to pay (first suggested amount) won for the remodeling?
1) Yes (go to Q6-1)
2) No (go to Q6-2)

Q6-1. Then, are you willing to pay (twice the first suggested amount) won for the remodeling?
1) Yes
2) No

Q6-2. Then, are you willing to pay (half of first suggested amount) won for the remodeling?
1) Yes
2) No 